\title{
An upstream activating sequence containing curved DNA involved in activation of the Clostridium perfringens plc promoter
}

\author{
Chieko Matsushita, ${ }^{1}$ Osamu Matsushita, ${ }^{1}$ Seiichi Katayama, ${ }^{1}$ \\ Junzaburo Minami, ${ }^{1}$ Kenichi Takai ${ }^{2}$ and Akinobu Okabe ${ }^{1}$
}

Author for correspondence: A. Okabe. Tel: +81878985111 . Fax: +81 878987109.

e-mail: microbio@kms.ac.jp

\footnotetext{
1 Department of Microbiology, Kagawa Medical School, 1750-1, Miki-cho, Kita-gun, Kagawa 761-07, Japan

2 Okayama Central Hospital, 2-18-19, Hokan-cho, Okayama 700, Japan
}

\begin{abstract}
The p/c gene, which encodes phospholipase C ( $\alpha$-toxin) of Clostridium perfringens, possesses three poly(A) tracts forming an intrinsically curved DNA region immediately upstream of the promoter. The in vivo transcriptional activity of the plasmid-borne p/c gene was stimulated by this curved-DNAcontaining sequence, depending on its proper linear and rotational orientation. The in vitro transcriptional activity of the plc gene was also stimulated by the upstream sequence. In addition, the stimulatory effect of the sequence and the degree of DNA bending were greater at lower temperature, as was demonstrated by both in vitro and in vivo transcription assays, and a gel-mobility assay, respectively. A similar temperature effect was also observed with the chromosomal plc gene. These observations suggest that the upstream DNA curvature per se stimulates the initiation of transcription of the plc gene, possibly through direct contact with RNA polymerase.
\end{abstract}

Keywords: curved DNA, gene expression, Clostridium perfringens, phospholipase C

\section{INTRODUCTION}

Clostridium perfringens is a spore-forming anaerobic bacterium which is widely distributed in nature, and also lives in the large intestines of humans and other animals. It sometimes causes histolytic infections such as gas gangrene upon infecting a host. Since phospholipase C (PLC; EC 3.1.4.3) is the most important virulence factor of the organism (Hatheway, 1990; Titball, 1993; Ninomiya et al., 1994), PLC production seems to be critically important to the host-parasite interrelationship. Although the PLC-encoding gene $(p l c)$ has been cloned and sequenced (Leslie et al., 1989; Okabe et al., 1989; Saint-Joanis et al., 1989; Titball et al., 1989; Tso \& Siebel, 1989), the regulation of plc gene expression is not well understood.

In a previous paper (Toyonaga et al., 1992), we reported that three poly $(\hat{A})$ tracts, with a 10 or 11 bp periodicity located immediately upstream of the $p l c$ promoter $\left(\mathrm{P}_{p l c}\right)$ form an intrinsic DNA curvature. Since intrinsically curved DNA located upstream of a promoter enhances the activities of downstream promoters (Pérez-Martín $e t$

Abbreviations : PLC, phospholipase $C_{;} P_{\rho l c}$ promoter of the plc gene. al., 1994), it seems likely that expression of the plc gene is also stimulated by the curved DNA. To prove this, we examined the in vivo effect of the upstream curved DNA on the transcriptional activity of $\mathrm{P}_{\text {pic }}$ using two sets of mutant plasmids, one with deletions of the poly (A) tracts, and the other with oligonucleotide inserts of various lengths between the tracts and the -35 sequence.

Curved DNA containing-fragments show anomalously slow electrophoretic mobility at low temperature. This gel migration anomaly has been suggested to be due to conformational changes of the curved DNA induced by a decrease in temperature (Diekmann, 1987; Koo \& Crothers, 1988). Therefore, it is conceivable that the curved DNA per se modulates the promoter activity in response to changes in temperature. In order to assess this possibility, $C$. perfringens strain $13 \mathrm{PJ}^{-}$containing plasmid-borne plc genes with and without the curved DNA was grown at various temperatures, and then the levels of $p l c$ transcripts in the cultures were determined. We also examined the in vitro transcriptional activity of these plc genes at different temperatures to rule out the possible involvement of a DNA-binding protein in the observed temperature-dependent stimulatory effect.

This paper describes the stimulatory effect of the curvedDNA-containing upstream sequence on $\mathrm{P}_{p l c}$ activity and 
(a)
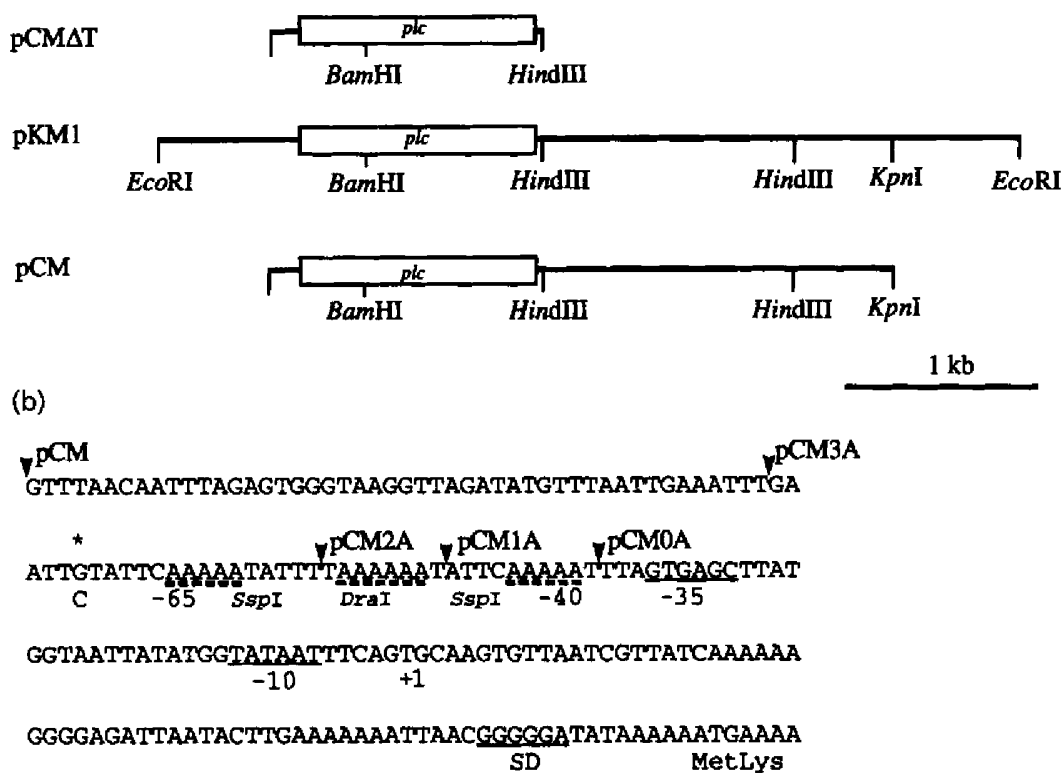

(c)

\begin{tabular}{|c|c|}
\hline pCM & AAAATATTTTAAAAAATATTCAAAAATTTAGTGACC \\
\hline pCM & AAAATATTTTAAAAATATTCAAAAATAGATCTTAGTGAGC \\
\hline pCM $\Omega 11$ & AAAAATATTTTARAAAATATTCAAAAATAGATCTGCGTATTAGTGAGC \\
\hline pCM $\Omega 15$ & AAAAATATTTTAAAAAATATTCAAAAATAGATCGATCTCCGTATTAGTGAGC \\
\hline & 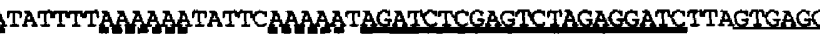 \\
\hline
\end{tabular}

modulation of the effect through its conformational change in response to a change in temperature.

\section{METHODS}

Bacterial strains, plasmids and growth conditions. The $C$. perfringens strains used in this study were NCTC 8237 (Okabe et al., 1989), and strain $13 \mathrm{PLC}^{-}$(Kameyama et al., 1996). The plo gene of the latter strain is disrupted by homologous recombination with pKMB141, a derivative of $\mathrm{pJIR} 418$, which lacks oriCP and contains a $376 \mathrm{bp}$ FokI fragment of the plo gene. Escherichia coli strain DH5 $\alpha$ (Hanahan, 1985) was used to construct plasmid derivatives. E. coli BMH 71-18 muts, which was used for site-directed mutagenesis, was obtained from Clontech Laboratories. Plasmid pJIR418 (Sloan et al., 1992) was used as an E. coli $C$. perfringens shuttle plasmid. The following two plasmids were used to construct pJIR418 derivatives: pCM $\mathrm{T}$, pJIR418 into which a $1.5 \mathrm{~kb}$ fragment containing the plc gene was cloned from C. perfringens NCTC 8237 (Toyonaga et al., 1992); and pKM1 (Okabe et al., 1989), pBR322 into which a $4.4 \mathrm{~kb}$ EcoRI fragment containing the $p l c$ gene was cloned from NCTC 8237 . C. perfringens strains were grown anaerobically in GAM broth (Nissui Pharmaceutical) with and without $10 \mu \mathrm{g}$ chloramphenicol $\mathrm{ml}^{-1}$ and $20 \mu \mathrm{g}$ erythromycin $\mathrm{ml}^{-1}$ (Matsushita et al., 1994a). E. coli strains were grown in Luria-Bertani broth (LB broth; Gibco) as described previously (Matsushita et al, 1994b).

Site-directed mutagenesis. This was performed using a Transformer site-directed mutagenesis kit (Clontech), according to the instruction manual of the manufacturer. An oligonucleotide containing a StuI site, 5' GAC'T'TGGT'TGAGGCCTCACCAGTCAC 3', was used as a selection primer. The following mutagenic primers were used to generate new restriction sites: (1) 5' GAAATTTGAATTCTATTCAAAAATA 3' for generation of a new EroRI site between nucleotide positions -77 and -72 relative to the plc transcriptional start; and (2) 5' AAAA AATATTCAAAAATAGATCTTAGTGAGCTTATG $3^{\prime}$ and 5' AAAAA TA T'TCAAAAATAGATCTGCGTATTAGT GAGCTTATG 3 ' for insertion of 5 and 11 nucleotides, respectively, which contained a $B g / I I$ site between nucleotide positions -39 and -38 relative to the $p l c$ transcriptional start. A DNA fragment prepared by annealing two synthetic oligonucleotides, 5' GATCTCGAGTCTAGAG $3^{\prime}$ and 5' GATCCTCTAGACTCGA 3', was also used to insert 16 nucleotides into the newly generated $B g / \mathrm{II}$ site.

Construction of mutant plasmids. pCM $\mathrm{T} T$ derivatives with deletions and insertions in the plc upstream region were constructed by cutting and rejoining at restriction sites of PCM $\triangle T$ and those generated by site-directed mutagenesis, and also by inserting synthetic oligonucleotides (see Fig. 1). Since PCM $\Delta T$ and its derivatives did not contain a plc transcriptional terminator, the $3^{\prime}$ end of the insert DNA in each construct was extended further downstream by replacing a $1.0 \mathrm{~kb} \mathrm{BamHI-}$ $K p n I$ fragment of each construct with a $2.8 \mathrm{~kb} \mathrm{BamHI}-K p n \mathrm{I}$ fragment of pKM1 containing the plc terminator (Fig. 1a). The set of pCM derivatives containing different numbers of poly $(A)$ tracts was designated as follows (see Fig. 1b): pCM, pCM3A, pCM2A, $\mathrm{pCM} 1 \mathrm{~A}$ and $\mathrm{pCM} 0 \mathrm{~A}$. The other set of $\mathrm{pCM}$ derivatives 
constructed with the insertion of oligonucleotides (see Fig. 1c) are called pCM 25 , $\mathrm{pCM} \Omega 11, \mathrm{pCM} \Omega 15$ and $\mathrm{pCM} \Omega 21$.

Determination of plc mRNA levels. When cultures of $C$. perfringens strains reached an $\mathrm{OD}_{600}$ of $0 \cdot 9-1 \cdot 0$, total RNA was prepared as described elsewhere (Katayama et al., 1993). Northern hybridization was performed as described previously (Matsushita $e t$ al., 1994b). The levels of $p l c$ transcripts were determined by quantitative Northern analysis using various amounts $(0 \cdot 125-1 \mu \mathrm{g})$ of RNA as described previously (Tsutsui et al., 1995).

Nucleotide sequencing and DNA manipulations. C. perfringens strains were transformed by a modification of the method of Allen \& Blaschek (1990). Restriction endonucleases and DNA modifying enzymes were purchased from Takara Shuzo, Toyobo and New England Biolabs. All recombinant DNA procedures were performed as described by Sambrook et al. (1989). The nucleotide sequence of each plasmid construct was determined as described previously (Matsushita et al., 1994b).

Gel mobility assay. To analyse the mobility of a curved-DNAcontaining fragment, $5 \%(\mathrm{w} / \mathrm{v})$ polyacrylamide [acrylamide/ bisacrylamide $=29 \cdot 2: 0 \cdot 8(\mathrm{w} / \mathrm{w})]$ gel electrophoreses were performed in $45 \mathrm{mM}$ Tris/borate, $\mathrm{pH} 8.0$ and $1 \mathrm{mM}$ EDTA at $6 \mathrm{~V} \mathrm{~cm}^{-1}$. The temperature during the electrophoresis was kept constant $\left(25 \pm 0.5\right.$ or $\left.45 \pm 0.5^{\circ} \mathrm{C}\right)$ by means of an apparatus with a device for temperature regulation [Koike Precision Instruments, Kawasaki; model E-IES 17-20'TR (Matuo et al., 1982)]. Two plasmids, pCM $\triangle \mathrm{T}$ and $\mathrm{PCM} \triangle \mathrm{T} 0 \mathrm{~A}$, wete used as the source of DNA containing the curved DNA and a control, respectively. Digests of these plasmid DNAs with PvuII and Nhel were electrophoresed. HinfI-digested pBR322 DNA was used as the unbent molecular mass marker. Semi-log plots of the telative gel mobilities of the fragments wete calibrated by leastsquares fitting. The apparent length of each fragment was then calculated from the least-squares calibration plot. The gel migration anomaly is presented in terms of $R_{L}$, which is defined as the ratio of the apparent to true fragment length.

Assays for PLC. Phospholipase $C$ activity in the culture supernatant was assayed by the method of Kutioka \& Matsuda (1976) using $p$-nitrophenylphosphorylcholine (Sigma) as a substrate. Cellular protein concentration was determined as described previously (Katayama et al., 1993).

In vitro transcription assay. Template $\mathrm{DN} A$ s were prepared by digesting pCM $\triangle \mathrm{T}$ and pCM $\triangle \mathrm{TOA}$ with PyII and $A \Leftrightarrow \mathrm{II}$, followed by electroelution of 335 and $245 \mathrm{bp}$ fragments, respectively. RNA polymerase was prepared from $C$. perfringens NCTC 8237 cells as described by Garnier \& Cole (1988). The in vitro transcription assay was performed as described elsewhere (Garnier \& Cole, 1988) except that $40 \mathrm{ng}$ DNA template and $1 \mu \mathrm{g}$ RNA polymerase were used. The relative amounts of the pic transcripts were determined with a Fuji BAS1000 Bio-image analyser (Fuji Photo Film).

\section{RESULTS}

\section{Effects of deletions and insertions on the p/c promoter activity}

In order to determine whether or not the poly(A) tracts immediately upstream of $\mathrm{P}_{p l c}$ stimulate the transcriptional activity of $\mathrm{P}_{p l c}, \mathrm{pCM}$ derivatives with deletions and insertions in the plc upstream region were constructed (Fig. 1). The identities of all mutations generated were confirmed by nucleotide sequencing of each construct. The DNA curvature present in the derivatives with
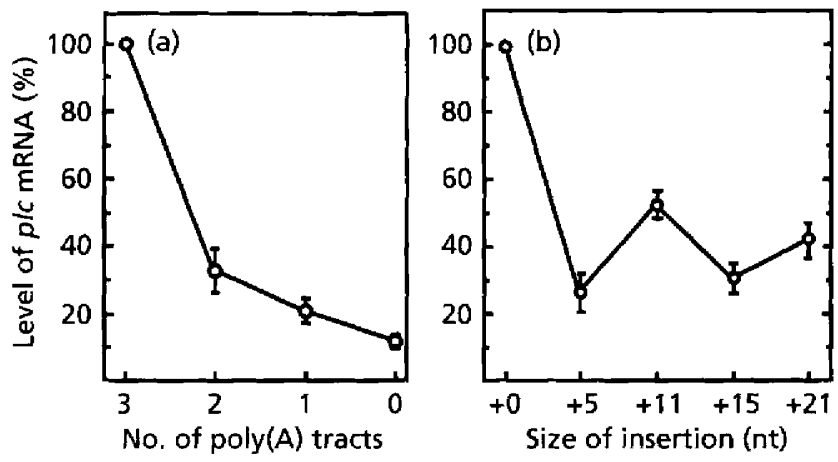

Fig. 2. Effects of (a) deletion of poly(A) tracts and (b) insertion of 5 to $21 \mathrm{bp}$ between the curved DNA and the -35 sequence on transcription of the p/c gene. $C$. perfringens strain $13 \mathrm{PLC}^{-}$ harbouring pJIR418 and its derivatives were grown in GAM broth with antibiotics at $37^{\circ} \mathrm{C}$. RNA was extracted when the cultures reached an $\mathrm{OD}_{600}$ of 0.9-1. The relative amounts of p/c mRNA were determined by quantitative Northern analysis, as described in Methods. Data are expressed as mean \pm SD (bars) for triplicate determinations.

deletions was examined by determining the gel mobilities of fragments containing poly $(\mathrm{A})$ tracts at the centre. The $R_{L}$ value decreased as the number of residual poly $(A)$ tracts decreased (data not shown). All the $\mathrm{PCM}$ derivatives were introduced into $C$. perfringens strain $13 \mathrm{PLC}^{-}$and then in wivo transcription of the plasmid-borne plc genes was examined. When the three poly $(A)$ tracts were deleted successively from the $5^{\prime}$ end, the level of plc mRNA decreased markedly (Fig. 2a). Deletion of the first poly(A) tract decreased the $\mathrm{P}_{p l n}$ activity to about $30 \%$ of the level of the wild-type having the three tracts. Deletion of the second and third tracts caused further decreases in the transcriptional activity, which finally fell to $10 \%$ of the wild-type level.

The number of tracts determines not only the bend angle, but also the span and the centre of the bend. Therefore, the question was raised as to whether or not the position of the bend is another important factor for the stimulatory effect. To assess this possibility, we examined the effect of insertional mutations on the plc gene expression (Fig. 2b). All the inserts resulted in a marked decrease in the transcriptional activity of $\mathrm{P}_{p l c}$. Furthermore, the mutant promoters in which the curved DNA was rotated by one or two turns of the helix (i.e. 11 and 21 bp insertions) and was thus in the same phase as the wild-type, showed significantly higher activity than those in which the curved DNA was in the opposite phase (i.e. 5 and $15 \mathrm{bp}$ insertions). Therefore, appropriate placement of the curved DNA in terms of both linear and rotational orientation is required for its stimulatory effect on $\mathrm{P}_{p l c}$.

\section{$\mathbf{P}_{p l c}$ activities at different temperatures}

Curved-DNA-containing fragments exhibit anomalously slow mobility in an electric field at low temperature (below $6{ }^{\circ} \mathrm{C}$ ), but not at high temperature (above $50^{\circ} \mathrm{C}$ ). A more subtle change in the molecular shape of the 
Table 1. Comparison of the transcriptional activity at various temperatures between the wild-type and mutant plc genes

All assays were performed in triplicate using $0 \cdot 125-1 \mu \mathrm{g}$ RNA as described in Methods.

\begin{tabular}{|c|c|c|}
\hline \multirow{2}{*}{$\begin{array}{l}\text { Temp. } \\
\left({ }^{\circ} \mathrm{C}\right)\end{array}$} & \multicolumn{2}{|c|}{ Wild-type/mutant transcription ratio } \\
\hline & in vivo* & in vitro $†$ \\
\hline 25 & $8 \cdot 6 \pm 0 \cdot 4$ & $>9.3 \pm 0.1 \ddagger$ \\
\hline 30 & $7 \cdot 6 \pm 0.5$ & $7 \cdot 3 \pm 0 \cdot 9$ \\
\hline 37 & $6 \cdot 6 \pm 0.4$ & $6 \cdot 3 \pm 0 \cdot 6$ \\
\hline 41 & $4.5 \pm 0.4$ & ND \\
\hline 45 & $3 \cdot 8 \pm 0 \cdot 2$ & $3 \cdot 9 \pm 0 \cdot 8$ \\
\hline
\end{tabular}

ND, Not determined.

* The $\mathrm{PLC}^{-}$strain harbouring pCM (wild-type) or pCM0A (mutant) was grown at the indicated temperatures. The relative amounts of $p / c$ mRNA were determined in each culture. Values are expressed as the ratio of the relative amount of pli $\mathrm{mRNA}$ in pCM-containing cells to that in PCMOA-containing cells.

† Values are expressed as the ratio of the relative amount of plc mRNA transcribed from the pCM-derived template to that from the pCM0A-derived one.

$\ddagger$ The amount of $p l c$ mRNA was lower than the lowest value determined by the method.

curved DNA may be induced by changes in temperature in a narrower range, as has been demonstrated by Diekmann (1987) for synthetic curved DNAs. We performed gel mobility analyses of the curved DNA at 25 and $45^{\circ} \mathrm{C}$, two growth-permissive temperatures. The $R_{L}$ values of a $337 \mathrm{bp}$ fragment with the curved DNA determined at 25 and $45^{\circ} \mathrm{C}$ were $1 \cdot 29 \pm 0.01$ and $1 \cdot 09 \pm 0 \cdot 01$, respectively, while those of a $247 \mathrm{bp}$ fragment without the curved DNA at the two temperatures were both nearly $1\left(1.08 \pm 0.00\right.$ at $25^{\circ} \mathrm{C}$ and $1.03 \pm 0.00$ at $45^{\circ} \mathrm{C}$ ). This clearly indicates the conformation of the curved DNA changes even in such a natrow temperature range.

In order to determine the stimulatory effect of the curved DNA at different temperatures, we grew $C$. perfringens strain $13 \mathrm{PLC}^{-}$carrying pCM, a wild-type plasmid, at various temperatures between 25 and $45^{\circ} \mathrm{C}$, and then determined the level of $p / c$ mRNA in each culture. The level of plc mRNA decreased as the growth temperature increased. In contrast, in the case of $\mathrm{pCMOA}$, a mutant plasmid without the curved DNA, it was nearly constant at all the temperatures examined (data not shown). Since the RNA contents of cultures growing rapidly at high temperature may differ from those growing slowly at low temperature, the plc mRNA levels in the two different cultures grown at the same temperature were compared with each other (Table 1). 'The ratio of the mRNA level in the pCM-carrying cells to that in PCMOA-carrying ones increased with decreasing temperature. These results suggest that $p l c$ is expressed efficiently at lower temperatures, probably through the formation of a more suitable conformation of the curved DNA.

\section{In vitro transcription of the plc gene}

There is a possibility that a protein binding to the upstream region is involved in the effect of the curved DNA observed in the in vivo experiment. To eliminate this, the in vitro transcriptional activity of the wild type plc gene from pCM was compared with that of the mutant gene from $\mathrm{pCM} 0 \mathrm{~A}$. The relative amounts of $p l c$ transcripts from the former were higher than those from the latter at all the temperatures examined (Table 1). Moreover, the stimulatory effect of the curved DNA on the transcriptional activity was more prominent at low temperature than at high temperature (Table 1).

\section{Expression of the chromosomal plc gene at different temperatures}

To ascertain whether or not the chromosomal plc gene is also expressed in a temperature-dependent fashion, C. perfringens NCTC 8237 was grown at various temperatures, and then the levels of plc mRNA and PLC activity were determined. As shown in Table 2, lowering of the growth temperature increased the level of $p l c$ mRNA. PLC production was also higher at low temperature than at high temperature. The temperature effect on PLC production was not so prominent as that on plc gene transcription, which may be due to depression of the synthesis and secretion of PLC at low temperature.

\section{DISCUSSION}

The results presented here clearly indicate that a promoter upstream sequence with curved DNA stimulates the promoter activity of the plc gene which encodes PLC, a principal virulence factor of $C$. perfringens. They also indicate that the curved DNA in the sequence modulates it in a temperature-dependent manner. The promoter upstream DNA curvature has been postulated to facilitate the formation of the closed complex and thereby stimulate promoter activity (Pérez-Martín et al., 1994). However, this remains dubious because the $\mathrm{A}+\mathrm{T}$-rich binding site for the RNA polymerase $\alpha$ subunit (spanning positions -40 to -60 ), which functions as a third promoter recognition element (Ross et al., 1993; Rao et al., 1994), overlaps the DNA curvature. The third promoter recognition element may contribute partly to the stimulatory effect. However, the DNA curvature can be assumed to play an essential role in the stimulatory effect on plc gene expression for the following reasons. First, the stimulatory effect depends largely on the first poly(A) tract between positions -62 and -66 , as demonstrated by the deletion experiment. Second, the transcriptional activity of the $p l c$ gene is modulated by a change in temperature, correlating with the conformational change of the curved DNA, as was observed by gel-mobility analysis. Our interpretation is supported by the recent finding that curved DNA interacts with RNA polymerase further 
Table 2. Levels of plc mRNA and PLC activity in C. perfringens cultures grown at various temperatures

C. perfringens NCTC 8237 was grown to an $\mathrm{OD}_{600}$ of $0 \cdot 9-1 \cdot 0$ at the indicated temperatures. The levels of $p l c \mathrm{mRN} A$ and PLC activity were determined in two separate experiments. The values are the mean \pm SD for triplicate determinations.

\begin{tabular}{|c|c|c|c|}
\hline \multirow{2}{*}{$\begin{array}{l}\text { Temp. } \\
\left({ }^{\circ} \mathrm{C}\right)\end{array}$} & \multirow{2}{*}{$\underset{(\%)}{p l c \operatorname{mRNA}}$} & \multicolumn{2}{|c|}{ PLC activity $\dagger$} \\
\hline & & {$\left[(\mathrm{ml} \text { culture })^{-1}\right]$} & {$\left[(\mathrm{mg} \text { cellular protein })^{-1}\right]$} \\
\hline 25 & 100 & $1 \cdot 10 \pm 0 \cdot 00$ & $6.51 \pm 0.01$ \\
\hline 30 & $85 \pm 2 \cdot 5$ & $\mathrm{ND}$ & $\mathrm{ND}$ \\
\hline 37 & $47 \pm 2.5$ & $0.87 \pm 0.02$ & $4.92 \pm 0 \cdot 11$ \\
\hline 41 & $31 \pm 1 \cdot 5$ & $\mathrm{ND}$ & ND \\
\hline 45 & $23 \pm 0.5$ & $0.53 \pm 0.02$ & $2.63 \pm 0.06$ \\
\hline
\end{tabular}

* Relative amounts of plc mRNA are expressed as percentages of that in cells grown at $25^{\circ} \mathrm{C}$.

$\uparrow$ PLC activity in the culture supernatant was determined using $p$-nitrophenylphosphorylcholine as a substrate and expressed as nmol substrate hydrolysed $\mathrm{min}^{-1}$.

ND, Not determined.

upstream of the third element, forming a stable complex (Nickerson \& Achberger, 1995).

In the previous study (Toyonaga et al., 1992), we cloned the pli gene into a multi-copy plasmid, pUC19, and expressed it in E. coli, a heterologous host. We found that the synthesis of PLC by E. coli increased when the upstream region containing the poly(A) tracts was deleted (Toyonaga et al., 1992). The discrepancy seems to be due to the difference in the host/vector system in this and previous studies. This intrinsic DNA curvature present in the bla gene of pUC19 might indirectly affect expression of the cloned pli gene, as in the case of the curved DNA present in the lux $A B$ teporter system (Forsberg et al., 1994).

Many pathogenic bacteria regulate the expression of their virulence factors in response to changes in various environmental parameters such as temperature, osmolarity, ions, oxygen and $\mathrm{pH}$, all of which could be used as signals to detect entry into host tissues (Mekalanos, 1992). The transition from ambient low temperature to body temperature induces virulence genes in several organisms, e.g. genes of Sbigella fexneri involved in eukaryotic cell invasion and those of Pseudomonas aeruginosa in alginate capsule synthesis (Mekalanos, 1992). On the contrary, the intrinsic DNA curvature of the plo gene seemingly exerts an opposite effect in terms of the thermoregulation of virulence genes. C. perfringens is potentially highly virulent but usually avirulent, living as a commensal bacterium in the large intestines of humans and other animals. This organism can be expected to contribute to carcass putrefaction through the concerted actions of a variety of hydrolytic enzymes including PLC. Thus, to fulfil its commensal and saprophytic life styles, efficient expression of the plc gene at low temperature may be advantageous for the organism.

The present study focused on the function of the immediately adjacent upstream curved DNA in $\mathrm{P}_{\text {ple }}$ activity. Although curved DNA per se is unambiguously a cis-acting element activating $\mathrm{P}_{p l c}$ and contributes to the thermoregulation of the $p l c$ gene, the $p l c$ gene seems to be at least partly controlled by a complex mechanism involving trans-acting factors (Katayama $e t$ al., 1993) and a global-regulatory network (Rood \& Lyristis, 1995) governed by a two-component (VirR/VirS) system (Lytistis et al., 1994; Shimizu et al., 1994). Such regulatory systems would play a key role in pathogenicity of the organism upon infecting the host. Work aimed at the identification of trans-acting factors for the plc gene is now in progress.

\section{ACKNOWLEDGMENTS}

We are indebted to Thierry Garnier (Laboratoire de Génétique Moléculaire Bactérienne, Institut Pasteur) for helpful advice concerning the in vitro transcription assay. We also thank Akihisa Takamizawa and Masateru Akechi (Kanonji Institute, The Research Foundation for Microbial Diseases of Osaka University) for preparing the synthetic oligonucleotides. This work was supported by a Grant-in-Aid for Scientific Research from the Ministry of Education, Science and Culture, Japan.

\section{REFERENCES}

Allen, S. P. \& Blaschek, H. P. (1990). Factors involved in the electroporation-induced transformation of Clostridium perfringens. FEMS Mirrobiol Lett 70, 217-220.

Diekmann, S. (1987). Temperature and salt dependence of the gel migration anomaly of curved DN $A$ fragments. Nwleic Acids Res 15, 247-265.

Forsberg, A. J., Pavitt, G. D. \& Higgins, C. F. (1994). Use of transcriptional fusions to monitor gene expression: a cautionary tale. J Bacteriol 176, 2128-2132.

Garnier, T. \& Cole, S. T. (1988). Studies of UV-inducible promoters from Clastridium perfringens in vivo and in vitro. Mol Microbiol 2, 607-614. 
Hanahan, D. (1985). Techniques for transformation of E. coli. In DN A Choning: a Practical Appraach, vol. 1, PP. 109-135. Edited by D. M. Glover. Oxford: IRL Press.

Hatheway, C. L. (1990). Toxigenic clostridia. Clin Microbiol Rey 3, 66-98.

Kameyama, K., Matsushita, O., Katayama, S., Minami, J., Maeda, M., Nakamura, S. \& Okabe, A. (1996). Analysis of the phospholipase $C$ gene of Clostridium perfringens KZ1340 isolated from Antatctic soil. Microbiol Immunol 40, 255-263.

Katayama, S., Matsushita, O., Minami, J., Mizobuchi, S. \& Okabe, A. (1993). Comparison of the alpha-toxin genes of Clostriditum perfringens type $A$ and $C$ strains : evidence for extragenic regulation of transcription. Infoct Immun 61, 457-463.

Koo, H.-S. \& Crothers, D. M. (1988). Calibration of DNA curvature and a unified description of sequence-directed bending. Proc Nall Acad Sci USA 85, 1763-1767.

Kurioka, S. \& Matsuda, M. (1976). Phospholipase C assay using $p-$ nitrophenylphosphorylcholine together with sorbitol and its application to studying the metal and detergent requirement of the enzyme. Anal Biachem 75, 281-289.

Leslie, D., Fairweather, N., Pickard, D., Dougan, G. \& Kehoe, M. (1989). Phospholipase $C$ and haemolytic activities of Clostridium perfringens alpha-toxin cloned in Eschericbia coli: sequence and homology with a Bacillus cereus phospholipase C. Mol Microbiol 3, 383-392.

Lyristis, M., Bryant, A. E., Sloan, J., Awad, M. M., Nisbet, I. T., Stevens, D. L. \& Rood, J. I. (1994). Identification and molecular analysis of a locus that regulates extracellular toxin production in Clostridium perfringens. Mol Microbiol 12, 761-777.

Matsushita, C., Matsushita, O., Koyama, M. \& Okabe, A. (1994a). A Clostridium perfringens vector for the selection of promoters. Plasmid 31, 317-319.

Matsushita, O., Yoshihara, K., Katayama, S., Minami, J. \& Okabe, A. (1994b). Putification and characterization of a Clostridium perfringens 120 -kilodalton collagenase and nucleotide sequence of the corresponding gene. J Bacteriol 176, 149-156.

Matuo, Y., Nishi, N., Negi, T. \& Wada, F. (1982). Comparative analysis of subcellular proteins by SDS-polyacrylamide gel electrophoresis with dorsolateral and ventral prostates of rats. Electrophoresis 3, 293-299.

Mekalanos, J. J. (1992). Environmental signals controlling expression of virulence determinants in bacteria. J Bacteriol 174, 1-7. Nickerson, C. A. \& Achberger, E. C. (1995). Role of curved DNA in binding of Escbericbia coli RNA polymerase to promoters. J Bacteriol $177,5756-5761$.

Ninomiya, M., Matsushita, O., Minami, J., Sakamoto, H., Nakano, M. \& Okabe, A. (1994). Role of alpha-toxin in Clostridium perfringens infection determined by using recombinants of $C$. perfringens and Bacillus sabtilis. Infect Immun 62, 5032-5039.

Okabe, A., Shimizu, T. \& Hayashi, H. (1989). Cloning and sequencing of a phospholipase $C$ gene of Clostridium perfringens. Biochem Biophys Res Commun 67, 33-39.

Pérez-Martín, J., Rojo, F. \& De Lorenzo, V. (1994). Promoters responsive to DNA bending: a common theme in prokaryotic gene expression. Microbiol Rev 58, 268-290.

Rao, L., Ross, W., Appleman, J., Gaal, T., Leirmo, S., Schlax, P., Record, T. \& Gourse, R. L. (1994). Factor-independent activation of $r m B$ P1: an extended promoter with an upstream element that dramatically increases promoter strength. I Mol Biol 235, 1421-1435.

Rood, J. I. \& Lyristis, M. (1995). Regulation of extracellular toxin production in Clostridium perfringens. Trends Microbiol 3, 192-196.

Ross, W., Gosink, K., Salomon, J., Igarashi, K., Zhou, C., Ishihama, A., Severinov, K. \& Gourse, R. L. (1993). A third recognition element in bacterial promoters: DNA binding by the a subunit of RNA polymerase. Science 262, 1407-1413.

Saint-Joanis, B., Garnier, T. \& Cole, S. T. (1989). Gene cloning shows the alpha-toxin of Ciostridizm perfringens to contain both sphingomyelinase and lecithinase activities. Mol Gen Genet 219, 453-460.

Sambrook, J., Fritsch, E. F. \& Maniatis, T. (1989). Molecular Claning: a Laboratory Manual, 2nd ecin. Cold Spring Harbor, NY: Cold Spring Harbor Laboratory.

Shimizu, T., Ba-Thein, W., Tamaki, M. \& Hayashi, H. (1994). The vir $R$ gene, a member of a class of two-component response regulators, regulates the production of perfringolysin $O$, collagenase, and hemagglutinin in Clostridium perfringens. J Bacteriol $176,1616-1623$

Sloan, J., Warner, T. A., Scott, P. T., Bannam, T. L., Berryman, D. I. \& Rood, J. I. (1992). Construction of a sequenced Clostridium perfringens-Eschericbia coli shuttle plasmid. Plasmid 27, 207-219.

Titball, R. W. (1993). Bacterial phospholipase C. Microbiol Rev 57, $347-366$

Titball, R. W., Hunter, S. E. C., Martin, K. L., Morris, B. C., Shuttleworth, A. D., Rubidge, T., Anderson, D. W. \& Kelly, D. C. (1989). Molecular cloning and nucleotide sequence of the alphatoxin (phospholipase C) of Clostridium perfringens. Infect Immun 57, $367-376$.

Titball, R. W., Yeoman, H. \& Hunter, S. E. C. (1992). Gene cloning and organization of the alpha-toxin of Clostridium perfringens. In Genetics and Molecular Biology of Anaerobic Bacteria, pp. 211-226. Edited by M. Sebald. New York: Springer-Verlag.

Toyonaga, T., Matsushita, O., Katayama, S., Minami, J. \& Okabe, A. (1992). Role of the upstream region containing an intrinsic DNA curvature in the negative regulation of the phospholipase $\mathrm{C}$ gene of Clostridium perfringens. Microbiol Immunol 36, 603-613.

Tso, J. Y. \& Siebel, C. (1989). Cloning and expression of the phospholipase $C$ gene from Clostridium perfringens and Clostridizm bifermentans. Infect Immun 57, 468-476.

Tsutsui, K., Minami, J., Matsushita, O., Katayama, S., Taniguchi, Y., Nakamura, S., Nishioka, M. \& Okabe, A. (1995). Phylogenetic analysis of phospholipase $C$ genes from Clostridium perfringens types A to $\mathrm{E}$ and Clostridium noyyi. J Bacteriol 177, 7164-7170.

Received 29 January 1996; revised 10 April 1996; accepted 22 April 1996. 